\title{
The Effects of Post-Harvest Treatments on the Quality Characteristics of Citrus Fruits (Oranges)
}

\author{
Ogoe, Patrick Bentil \\ Department of Sciences, Komenda College of Education \\ Komenda, Ghana \\ Email: patrickbentilogoe [AT] gmail.com
}

\begin{abstract}
Citrus fruits have been one of the major food produced in the Abura-Asebu-Kwamankese and Mfantseman Districts. There has been a major concern about the production, harvesting, packaging, processing, and marketing of citrus fruits as well as the improvement of the citrus industry in the country. With high demand and popular dietary preferences, citrus fruit is widely consumed and has become an inseparable part of our diets. This called for the study of the effects of post-harvest treatments on the quality characteristics of the citrus fruits (oranges) in the Abura-Asebu Kwamankese and Mfantseman Districts in the Central Region of Ghana. From the findings, whether the fruits go through the covered treatment process or sun treatment process they all have effects on the citrus fruit qualities. However, it was observed that leaving the fruits in the sun has more adverse effects on the fruit quality characters such as fruit juice content, fruit weight, vitamin C, Total Titratable Acidity, and Total Soluble Solid (Brix). It is, therefore, recommended that farmers should be encouraged to cover their fruits after harvest.
\end{abstract}

Keywords--- Harvesting, Post-Harvest Treatment, Citrus, Processing, Quality

\section{INTRODUCTION}

Citrus fruits or their products are being part of the daily human intake in one or the other forms all over the world hence are recognized as important components in human health. The growing of citrus is not only a source of income to the growers but also has some socio-economic importance in the life of the people. It has a great employment opportunity, provides raw materials to the citrus-based industry, and having nutritive, medicinal values and a source of prosperity (Orlando, 2004).

With high demand and popular dietary preferences, citrus fruit is widely consumed and has become an inseparable part of our diets. Recent developments in horticultural utilization and improved analytical technology have helped establish the analysis of citrus fruit chemical constituents. According to Beatriz and Luis (2004), citrus fruits are characterised by their distinctive flavour. Citrus fruits are a good source of carbohydrates, dietary fibre, B vitamins, minerals, and biologically active phytochemicals such as carotenoids and flavonoids, which provide provitamin A activity and purported antioxidant benefits, respectively. Such nutrient density, low fat, low-sodium profiles, and associations between citrus fruit intake and prevention of chronic diseases make the promotion of citrus consumption important in improved human health.

In addition, Aslin (2014) added that citrus fruits have anti-cancer, anti-septic and anti-oxidant properties. They also provide natural refreshment to the skin. Moreover, since in 2010 the Mediterranean diet was recognized as an intangible cultural heritage by UNESCO, particular attention is paid to fruits nutraceutical characteristics. Indeed, not only in the Mediterranean but all over the world. Citrus fruits are a fundamental source of antioxidants and bioactive compounds, and their consumption has been related to the prevention of several diseases such as obesity, diabetes, cardiovascular diseases, and certain types of cancer (Benavente-García \&Castillo, 2008; Schroeder, 2007; Vanamala, et al ., 2006).

Different quality attributes are required of the citrus fruits for the fresh market, like the barometric parameters, or for industrial use. This makes the quality characteristics of citrus fruits very important in the horticultural business.

The quality of fresh commodities is defined by a combination of characteristics, attributes, and properties that give the commodity value as food. Producers are concerned that their commodities have a good appearance and few visual defects, but for them, a useful cultivar must score high in yield, disease resistance, ease of harvest, and shipping quality. To receivers and market distributors, appearance quality is most important; they are also keenly interested in firmness and long storage life. Consumers consider good quality fruits and vegetables to be those that look good, are firm, and offer good flavour and nutritional value. If a product is not safe it does not matte its quality; it should be eliminated from the product distribution system.

The method of harvesting (hand vs. mechanical) can significantly impact the composition and post-harvest quality of fruits. Management of harvesting operations, whether manual or mechanical, can have a major impact on the quality of harvested fruits. Proper management procedures include the selection of optimum time to harvest concerning product maturity and climatic conditions, training, and supervision of workers, and proper implementation of effective quality control. 
All citrus fruits must be picked, handled, and packed properly to avoid damage or potential damage when storing and transporting to the market. Many factors affect fruit quality, viz bad weather patterns, cultivars, rootstock, cultural practices, water management, nutrition, pests, and diseases. These challenges especially pests and diseases compel growers to treat the fruit to maintain its quality. Citrus fruit quality depends on the external appearance-fruit size, rind colour, and the degree of rind blemishes and the internal fruit quality-Total Soluble Solids (TSS), acids, plus the degree of sourness or aromaticity (Kader, 2002).

Over the past few years, food safety has become and continues to be the number one concern of the fresh produce industry. A post-harvest treatment is designed to minimize product contamination and maximize quality. Citrus fruits undergo various postharvest treatments to reduce microbial contamination, minimize water loss, and reduce ethylene damage, for decay control and insect control (Adel \& Rosa, 2004). Again, there are other postharvest treatments designed to manipulate the environment around produce to enhance the citrus fruit quality. Such treatments are supplements to keeping fresh horticultural perishables within their optimum ranges of temperature and relative humidity, controlled atmospheres (CA) or modified atmospheres (MA) can serve to extend their post-harvest shelf life.

Several factors influence the content of quality characteristics in fruit products, such as differences in genotype, pre-harvest climatic conditions, cultural practices, maturity, harvesting methods, and postharvest handling procedures (Cepeda et al., 1993). For example, Lee and Kader, 2000) noted that vitamin C can be increased when the intensity of light is high and high rates of nitrogen fertilizers may decrease the vitamin $C$ content in many fresh commodities, and losses of vitamin $C$ in fresh commodities are enhanced by extended storage, higher temperatures, low relative humidity, physical damage. Currently, ascorbic acid is the most widely used vitamin $\mathrm{C}$ supplement worldwide. It has been known for many years that citrus is a valuable source of ascorbic acid (vitamin C). Schröeder, (2007) believes that the stability of ascorbic acid in citrus fruits however depends markedly on the $\mathrm{pH}$ and oxygen content of the citrus fruit. Cepeda, et al, (1993) observed that ascorbic acid contents decrease with time of maturity in late Valencia citrus fruits. Muhamad and Nasir (2006) also indicated that orange $\mathrm{pH}$ varies significantly depending on the degree of maturity or ripeness or their variety but in general, the $\mathrm{pH}$ value of ripe orange ranges from 3.6 to 4.3 .

With the importance of citrus in this modern life of the people of Ghana and the scarcity of studies on the harvesting and postharvest treatments on citrus fruits and more specifically oranges, studies to addressing this issue become relevant. In this context, the work is aimed to investigate the effects of post-harvest treatments on the quality characteristics of orange fruits.

\section{THE PURPOSE OF THE STUDY}

The main purpose of this study was to investigate the effects of post-harvest treatments on the quality characteristics of the citrus fruits (oranges) in the Abura-Asebu Kwamankese and Mfantseman Districts in the Central Region of Ghana.

\section{OBJECTIVES OF THE STUDY}

1. Identify post-harvest treatments used by the citrus farmers.

2. Determine whether post-harvest treatments have effects on the fruits' quality characteristics.

\section{Laboratory analysis}

\section{MATERIALS AND METHODS}

The laboratory design was structured to determine the effects of postharvest treatments (i.e. covering and uncovering of the fruits after harvesting) on the citrus fruit quality characteristics. The parameters assessed were; fruit weight, fruit diameter, juice volume, juice content, vitamin $\mathrm{C}, \mathrm{pH}$ value, Total Titratable Acidity (TTA), Total Soluble Solids (TSS), and shelf life. Three hundred and fifty (350) citrus fruits at a similar stage of maturity and size were selected randomly from two different postharvest treatments. Two hundred and ten (210) citrus fruits were used for harvesting methods laboratory analysis. Some of the quality characteristics of the fruits, harvested by hand picking were analysed. Ten (10) fruits each from the two districts were selected for each experiment. Regarding postharvest treatments; covering and uncovering of the fruits after harvesting were analysed. One hundred and forty (140) citrus fruits were selected for the postharvest treatments. Ten (10) fruits were selected for laboratory analysis for each treatment.

The determination of the fruits' quality characteristics was done at the Horticulture Laboratory of the Department of Horticulture, Kwame Nkrumah University of Science and Technology, Kumasi, Ghana.

\section{Determination of Fruit weight and Fruit diameter}

Ten (10) samples of citrus fruits free from defects were used. The container that fruits would be weighed in was placed onto the weighing balance and tarred to zero $(0)$. The fruits were placed in the container and weighed, and the weight was recorded in grams $(\mathrm{g})$. The weighing was replicated three times and the average weight was taken. The diameters of the selected fruits were measured with a Vanier caliper. Each fruit was measured thrice and the average diameter was taken. 


\section{Determination of Juice weight and Juice Content}

The juice content is an essential parameter to determine the quality of different fruits, especially citrus fruits. Three fruits, representative from each of the harvesting treatments used were collected. The selected fruits were of similar size. In determining percentage juice content, the three representative fruits were weighed and recorded the combined weight in grams. The empty jug was weighed and the weight was recorded in grams. The fruit samples were placed into the jug, weighed and the weight recorded in grams $(\mathrm{g})$. The fruits were cut in halves and the juice was extracted from the three fruit samples using a juice extractor. The juice was strained and poured into the weighed jug and the juice was weighed and the weight recorded in grams. The percentage of juice was calculated as follows:

Juice percentage $=\frac{\text { Total weight of fruit juice }(\mathrm{g})-\text { Beaker weight }(\mathrm{g})}{\text { Total weight of fruit }(\mathrm{g})} \times 100$

\section{Determining Total Soluble Solids (\% Sugar or ${ }^{\circ}$ Brix)}

In the citrus industry, this is a measure of the total soluble solids in the juice. These soluble solids are primarily sugars; sucrose, fructose, and glucose. The Refractometer prism surface was cleaned and dried and a small amount of fresh juice was placed (a couple of drops is sufficient) onto the prism of the Refractometer. The eyepiece was looked through while pointing the prism in the direction of a good light source (not directly at the sun). The reading of where the base of the blue colour sits on the scale was recorded to represent the \% percentage sugar $\left({ }^{\circ}\right.$ Brix). The Refractometer was immediately cleaned with a damp tissue and dried thoroughly.

\section{Determining Total Titratable Acidity (TTA)}

The amount of acid present in the juice is reported as percent citric acid. To calculate this, titration with sodium hydroxide was used. $10 \mathrm{ml}$ of juice was pipetted into a clean conical flask and the pipette was cleaned immediately, after which 20 $\mathrm{ml}$ of distilled $\mathrm{H}_{2} \mathrm{O}$ was pipetted into the conical flask containing the juice. Six drops of phenolphthalein indicator were added and the mixture was carefully swirled then 6. 0.1 M sodium hydroxide solution was filled in the burette. The burette tap was opened to allow a trickle of sodium hydroxide $(\mathrm{NaOH})$ to run into a beaker. This was to ensure no air was in the burette before titration. The burette was refilled, making sure that it read zero at the top of the scale and the conical flask containing the juice mix was placed under the burette and while swirling, the sodium hydroxide was slowly added to the juice. The sodium hydroxide was added to the mixture in the flask while swirling until the colour changed to a persistent pink for at least 30 seconds and the volume was recorded.

The volume of sodium hydroxide added was multiplied by 0.064 to get the value of the acid (in grams per $100 \mathrm{ml}$ ).

\section{Calculations}

The \%TTA is calculated as: $\frac{\text { average titre } \mathrm{x} 0.0064 \text { (acid factor) }}{\text { Volume of solution }(10 \mathrm{ml})} \times 100$

\section{Procedure in determining sugar/acid ratio:}

"The sugar-acid ratio contributes to the unique flavour of citrus. To determine the sugar/acid ratio you need to divide the sugar concentration $\left({ }^{\circ}\right.$ Brix) by the citric acid concentration.

\section{Calculation}

$$
\mathrm{X}: 1 \text { sugar/acid ratio } \quad=\frac{\text { Sugar concentration }(\% \mathrm{Brix})}{10 \mathrm{ml} \text { of Juice }}
$$

\section{Determination of $\mathbf{p H}$}

Citrus juices from already blended fruits from each representative of the harvesting methods were poured into beakers. The $\mathrm{pH}$ electrode was dipped into the juice and $\mathrm{pH}$ readings were taken. The readings were taken three times for each and the average $\mathrm{pH}$ was recorded.

\section{Determination of Vitamin C content by titration (using Iodine Solution)}

One percent of starch Indicator solution and $0.50 \mathrm{~g}$ soluble starch were added to 50 near-boiling distilled water. The mixture was mixed well and allowed to cool before use (does not have to be $1 \%, 0.5 \%$ ). The next process was the use of Iodine Solution, 2.00g Potassium Iodide (KI) and 1.3g Potassium Iodide (KI) were dissolved in 100ml of distilled water. A few $\mathrm{ml}$ of distilled water was added and swirled for few minutes until iodine was dissolved. The solution was poured into a $1 \mathrm{~L}$ volumetric flask ensuring that all traces of the solution were rinsed into the volumetric flask using distilled water. The solution was topped up to the $1 \mathrm{~L}$ mark with distilled water.

Vitamin C standard solution was prepared with $0.250 \mathrm{~g}$ vitamin C (ascorbic acid) to dissolve in $100 \mathrm{ml}$ distilled water. The solution was diluted to $250 \mathrm{ml}$ with distilled water in a volumetric flask and labeled as Vitamin $\mathrm{C}$ standard solution. In 
standardizing solutions, $250.0 \mathrm{ml}$ of Vitamin C standard solution was added to a $125 \mathrm{ml}$ Erlenmeyer flask with $1 \mathrm{ml}$ of $1 \%$ starch solution added to it. The burette was rinsed with a small volume of the iodine solution and filled and the initial volume was recorded. The solution was titrated until the endpoint was reached. This was determined when the colour changed to black or a deepening of the initial colour in the case of coloured solutions. The final volume of the iodine solution was recorded. The initial volume minus the final volume was the volume required. The titration was repeated twice ensuring that the results were agreed within $0.1 \mathrm{ml}$.

Titration calculations

The $\mathrm{ml}$ of titrant used for each flask was calculated and the average measurements obtained were taken and the concentration of iodine was determined using $\mathrm{C}_{1} \mathrm{~V}_{1}=\mathrm{C}_{2} \mathrm{C}_{2}$

Where $\mathrm{C}_{1}=$ concentration of standard ascorbic acid.

$\mathrm{V}_{1}=$ volume of ascorbic acid.

$\mathrm{C}_{2}=$ unknown volume of iodine.

$\mathrm{V}_{2}=$ volume of iodine.

The calculated concentration of iodine was used to determine the concentration of the juice and the Vitamin $\mathrm{C}$ content in $\mathrm{mg} / 100 \mathrm{ml}$.

\section{RESULTS}

The summary of the results and analysis were presented below.

\section{Effects of postharvest treatments on fruit weight}

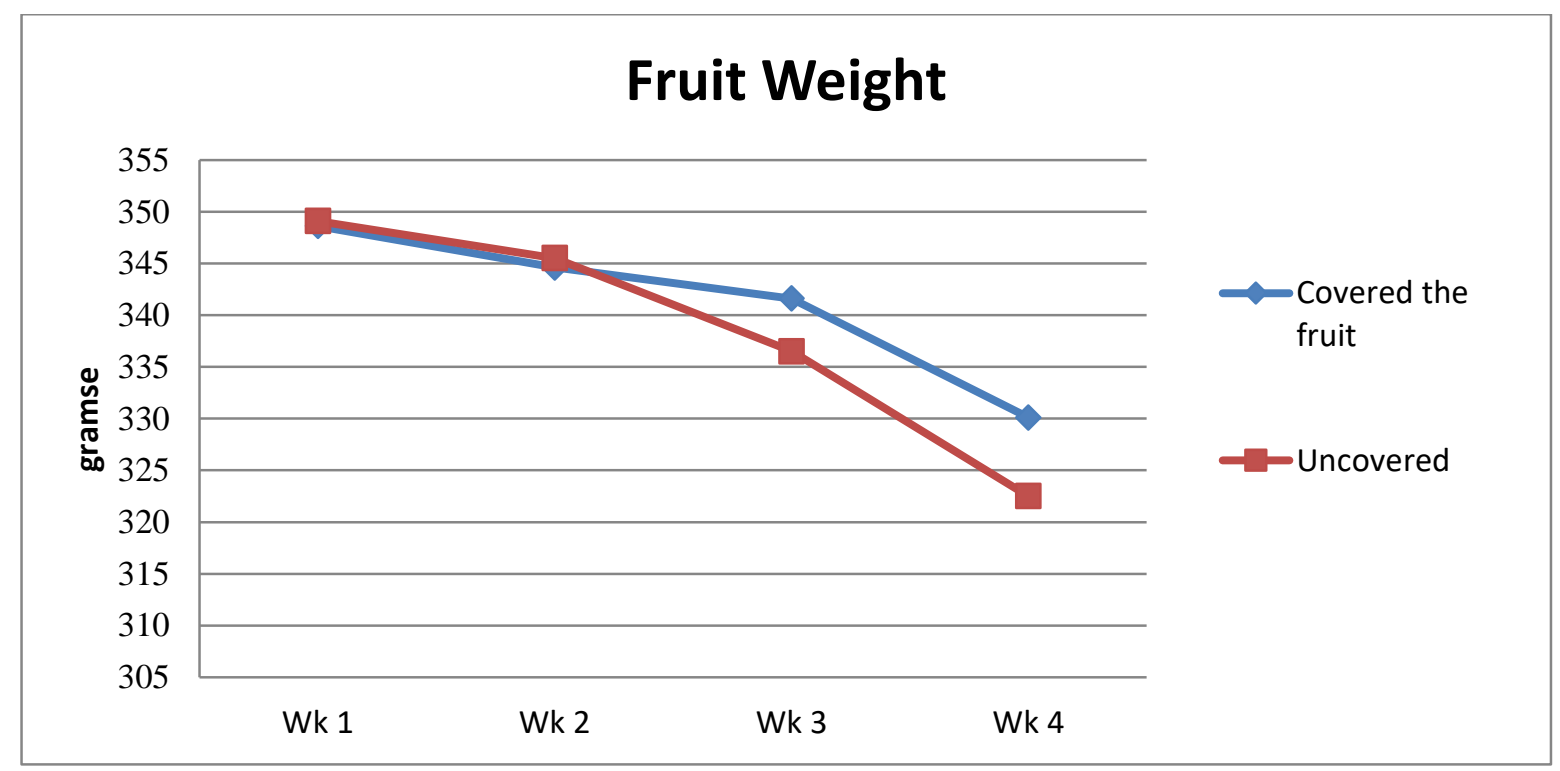

Figure 1: Effects of postharvest treatments on fruit weight

From figure 1, the weight of the uncovered fruits (exposed to the sun) declined from $348.6 \mathrm{~g}-3330.6 \mathrm{~g}$ at the beginning of the first week to the fourth week. The covered fruits also declined from $349.1 \mathrm{~g}$ to $322.2 \mathrm{~g}$. Both treatments gradually decreased in weight right from the first week. From the second week, the differences in weight loss became clear till week 4. The weight of the covered fruits at the beginning was $348.6 \mathrm{~g}$, in the second week it had reduced to $344.6 \mathrm{~g}$. It continued losing weight in week $3(341.6 \mathrm{~g})$ and week $4(330.1 \mathrm{~g})$. The uncovered fruits started losing weight in the first week from $349.1 \mathrm{~g}$ to $345.5 \mathrm{~g}$ in week 2 . At the end of week 4, the weight of the fruits had reduced from $349.1 \mathrm{~g}$ in week 1 to $322.2 \mathrm{~g}$. From the findings, the rate at which weight loss occurred in the uncovered fruits which are $7.61 \%$ was at a faster rate than the covered fruits $(5.30 \%)$. 


\section{Effects of postharvest treatments on fruit diameter}

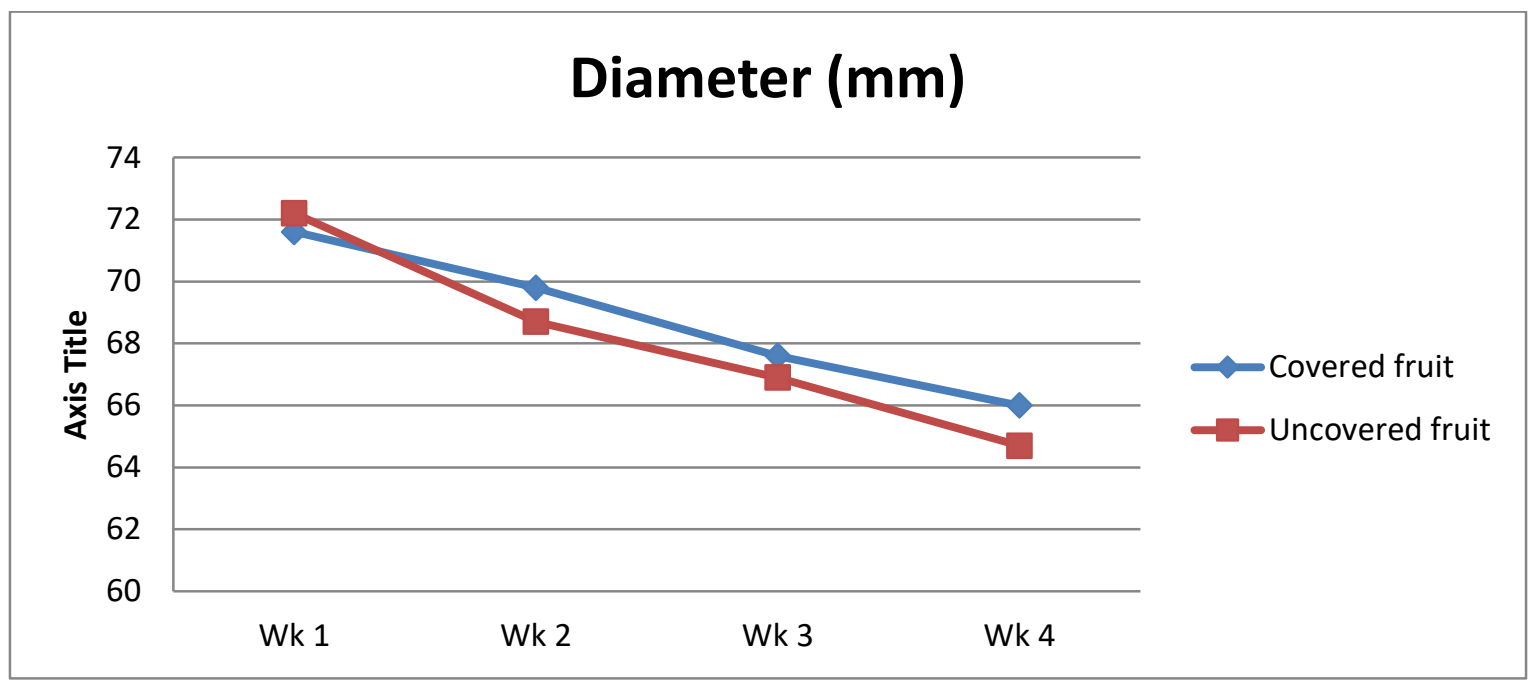

Figure 2: Effects of postharvest treatments on fruit diameter.

From figure 2, the diameter for the covered fruits ranged from $72.9 \mathrm{~mm}$ to $66.0 \mathrm{~mm}$ and the uncovered fruits also ranged from $72.2 \mathrm{~mm}$ to $64.7 \mathrm{~mm}$, from the beginning of the first week to the fourth week. Regarding covering treatment (covered fruits), the total average diameter was $72.9 \mathrm{~mm}$ at week 1 and it reduced to $69.8 \mathrm{~mm}$ in week 2 and $67.6 \mathrm{~mm}$ in week 3 . As of week 4 , it has reduced to 66.0. From the results, the uncovered fruits also had an average diameter of 72.2 at week 1 . It also reduced to $68.7 \mathrm{in}$ week 2, $66.9 \mathrm{in}$ week 3, and $64.7 \mathrm{~mm}$ in week 4. Even though in both treatments there was a reduction in diameter, but it was higher in the uncovered fruits than the covered fruits. From the findings, the rate at which weight loss occurred in the uncovered fruits which are $12.53 \%$ was at a faster rate than the covered fruits $(9.46 \%)$.

Effects of postharvest treatments on fruit juice content.

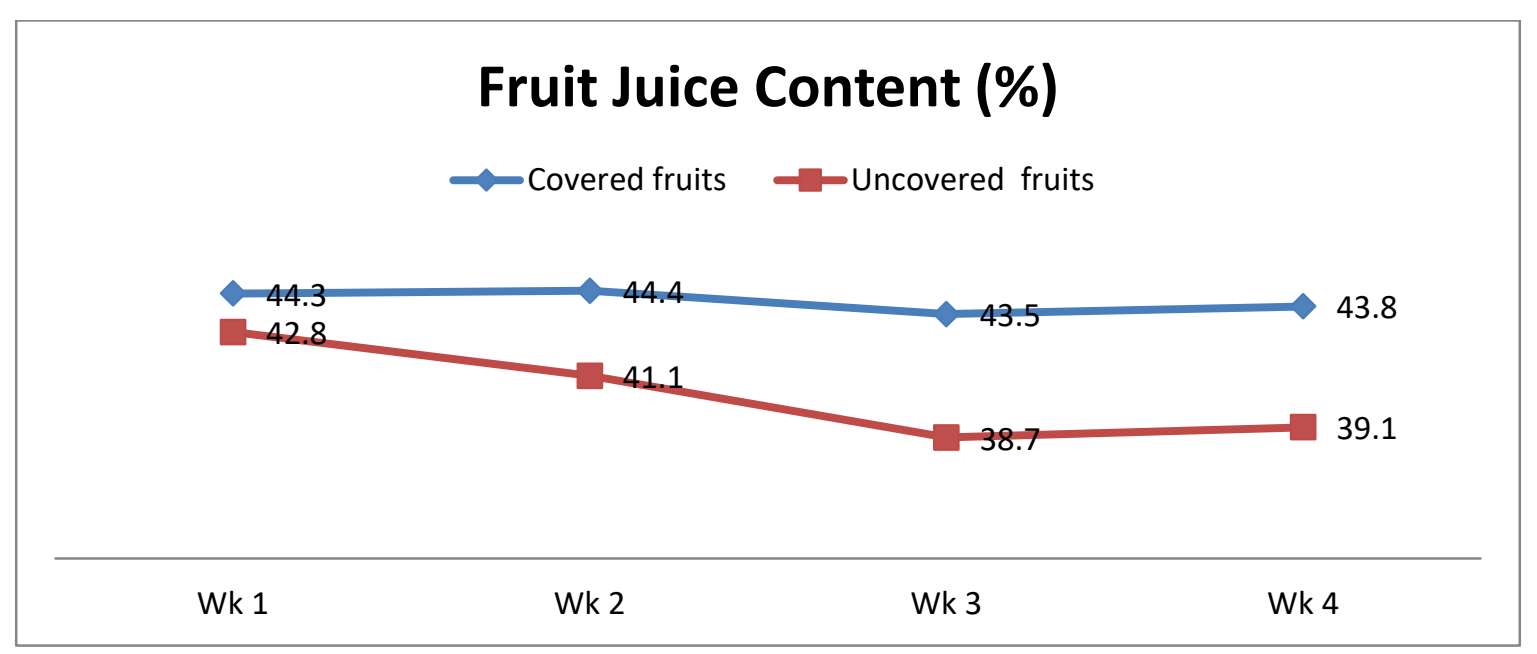

Figure 3: Effects of postharvest treatments on fruit juice content.

Regarding fruit juice content in the covering treatment method, there was not much reduction in the fruit juice. The average fruit juice content was $44.3 \%$ in week 1, 44.4 in week 2, 43.5 in week 3, and 43.8 in week 4. However, much decrease was seen in the uncovered treatment method. The average fruit juice content for week 1 was $42.8,41.1$ in week $2,38.7$ in week 3 , and 39.1 in week 4 . Indeed, there was inconsistency in both covered and uncovered treatments. From figure 3 , it decreased from week 1 to week 3 but there was an upward adjustment in week 4. From the findings, covering fruits does not affect fruit juice content $(0.6 \%$ reduction) but exposing the fruit to the sun had a significant effect of $7.24 \%$. 


\section{Effects of postharvest treatments on Vitamins C}

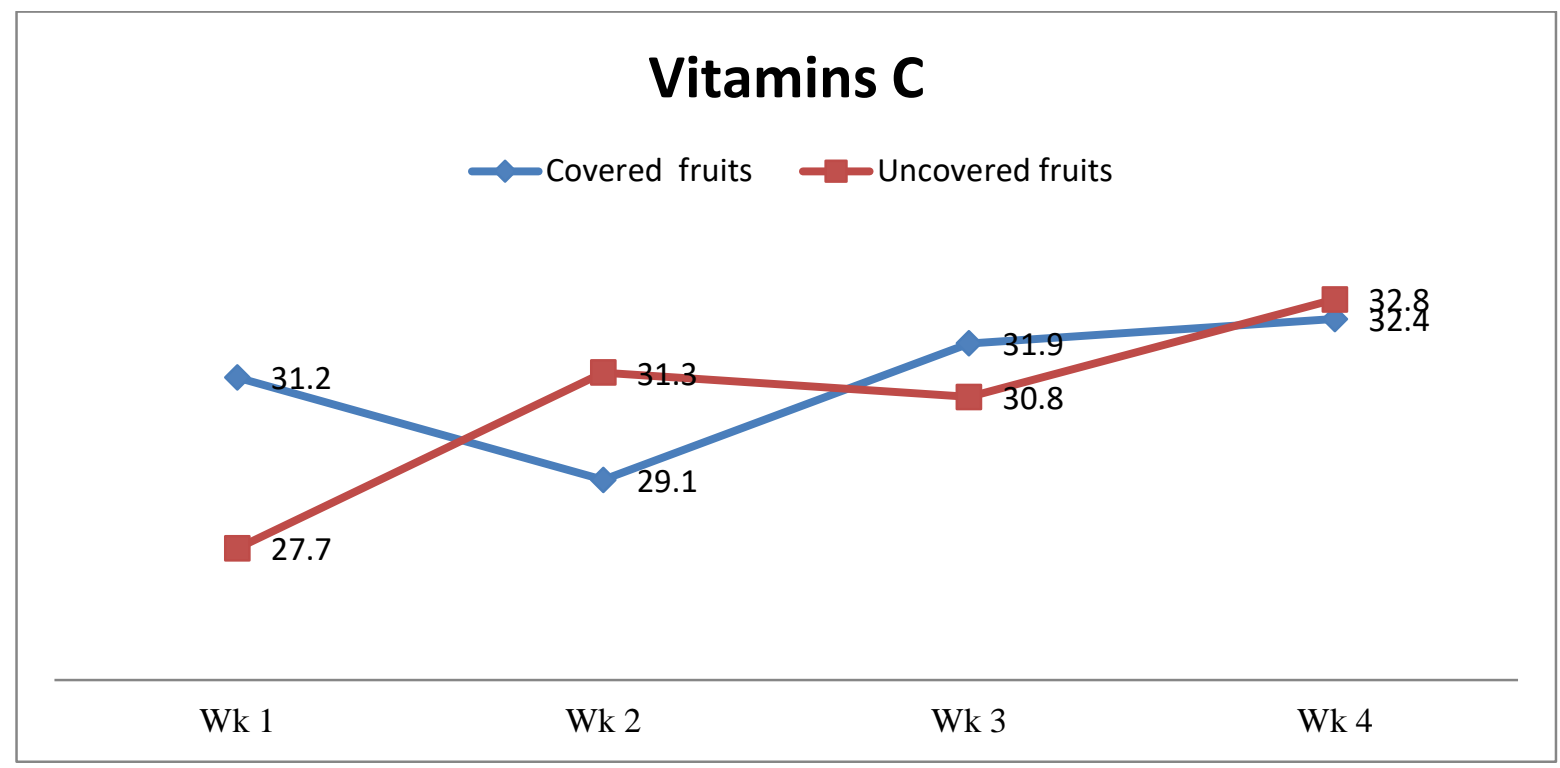

Figure 4: Effects of postharvest treatments on Vitamins C.

Figure 4 shows some inconsistencies in both covering and uncovering treatments on fruit vitamin $\mathrm{C}$ content. In the four weeks duration, covered fruits produced an average vitamin $\mathrm{C}$ of 31.2 in week 1, 29.1 in week 2, 31.9 in week 3 , and 32.4 in week 4. The uncovered treatment also gave 27.7 in the first week, 31.3 in the second week, and 30.8 in the third week, and 32.8 in the fourth week. From week 1, vitamin C started decreasing in the covering method and started increasing from the second week till the fourth week. On the other hand, it started increasing from week 1 in the uncovered method till the fourth week even though the margin was not great.

\section{Effects of postharvest treatments on $p H$}

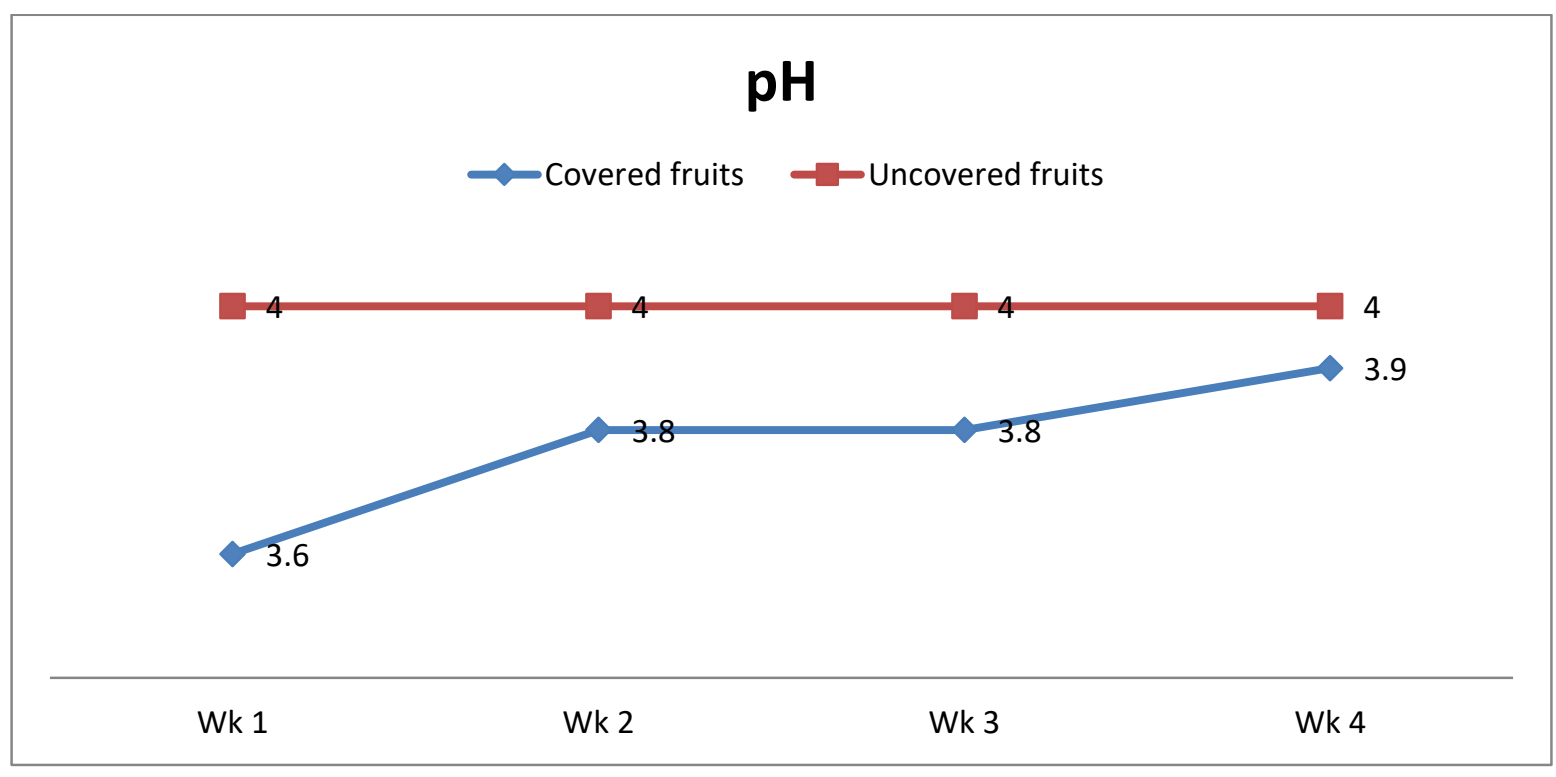

Figure 5: Effects of postharvest treatments on $\mathrm{pH}$

The $\mathrm{pH}$ values in the postharvest treatments became an interesting issue. The $\mathrm{pH}$ value in the covering treatment was a little bit higher than that of the uncovering treatment. The $\mathrm{pH}$ values of the covered fruits started from 3.6 in week $1,3.8$ in week 2, 3.8 in week 3 , and 3.9 in week 4 . Indeed, there was little increase $(0.8 \%)$ within the four weeks interval. In the case of the uncovered fruits, there was a constant $\mathrm{pH}$ value of 4 (figure 5) from week 1 to week 4. 
Effects of postharvest treatments on Total Titratable Acidity (TTA)

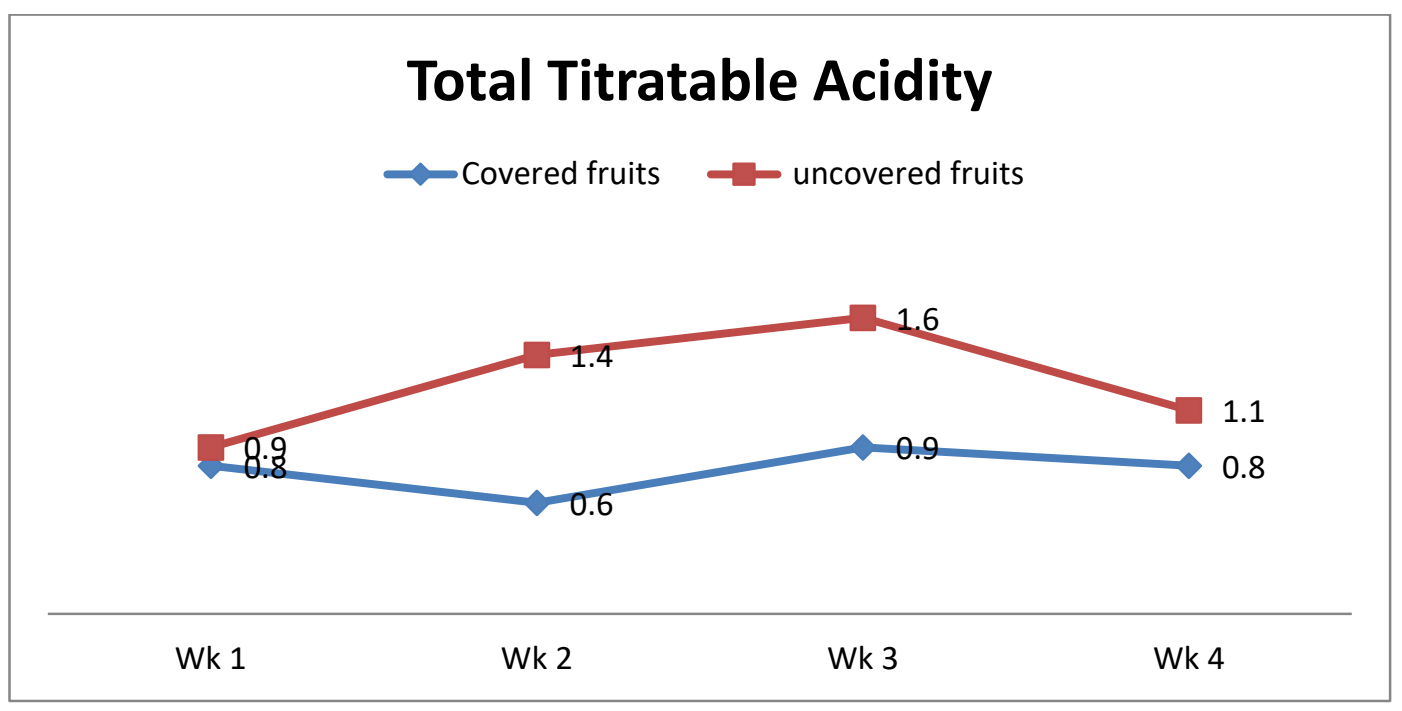

Figure 6: Effects of postharvest treatments on Total Titratable Acidity (TTA)

The effects of postharvest treatments on the fruits' Total Titratable Acidity also produced very interesting results. In the case of covering treatment method, 0.8 was obtained in week 1, 0.6 was obtained in week 2, 0.9 was obtained in week 3 and 0.8 was obtained in week 4 . As it can be seen in figure 6 , covered treatment started increasing in week 1 , but uncovered treatment started decreasing. The covered treatment made an upward adjustment from week 1 to week 3 and fell in week 4. During week 2, the uncovered treatment also started gaining an upward adjustment to week 3 and started falling from week 3 to week 4 (fig.6).

Effects of postharvest treatments on Total Soluble Solids $\left({ }^{\circ}\right.$ Brix $)$

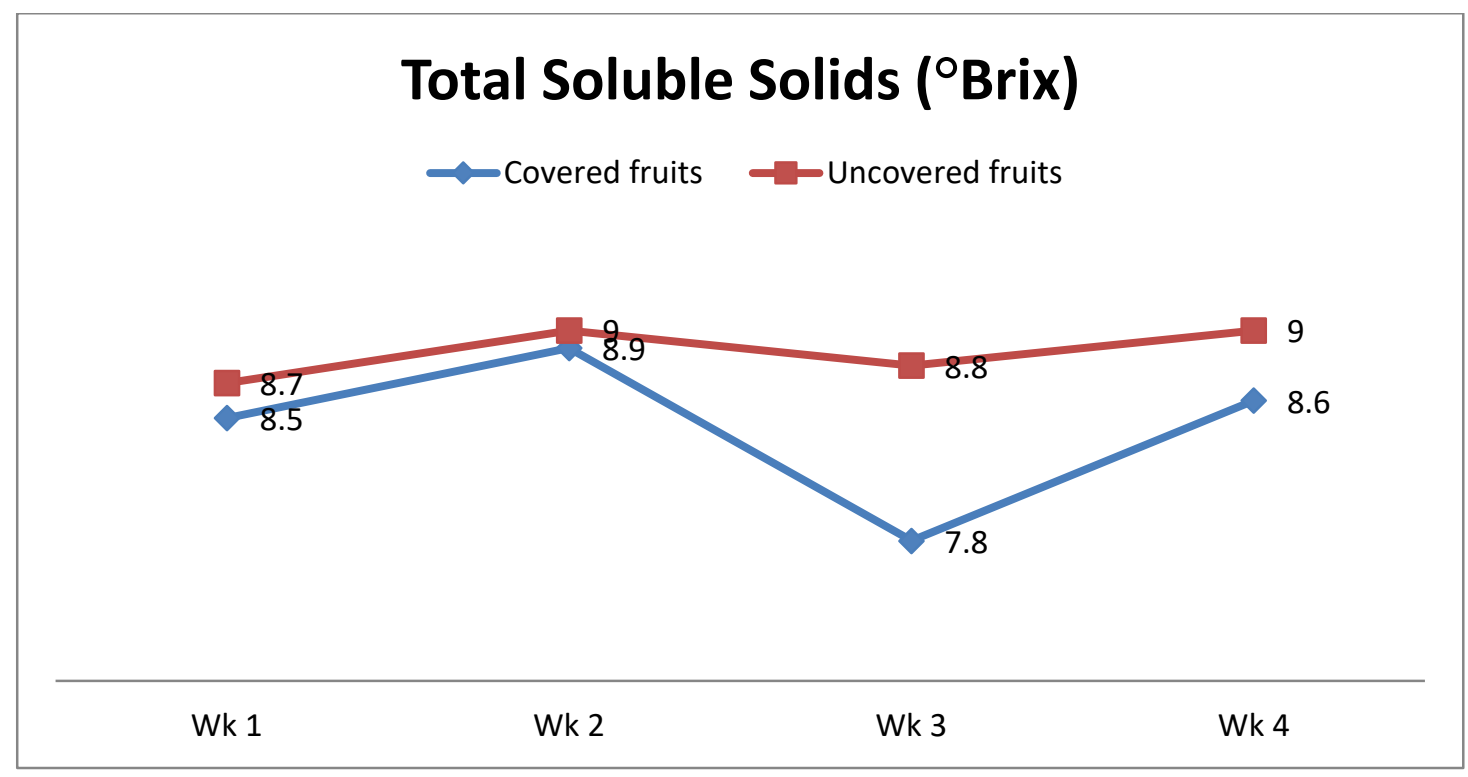

Figure 7: Effects of postharvest treatments on Total Soluble Solids ( ${ }^{\circ}$ Brix)

The results of postharvest treatments on the Total Soluble Solids for the covering and uncovering methods showed up and down movement (Fig. 7). In week 1, that of the covered fruits started rising from a value of 8.5 to a value of 8.9 and started downwards movement from week 2 to a value of 7.8 in week 3 . It then made an upward adjustment from 7.8 to 8.6 in week 4. However, the uncovered fruits started with a TSS value of 8.7 in week 1 and made an upward movement to a value of 9 in week 2 but fell to 8.8 in week 3 and made an upward movement again to 9 in week 4 . Even though there was a difference between the covered and the uncovered treatments but the difference was not that much (see fig 7). 


\section{DISCUSSION}

\section{Effects of the postharvest treatments on the quality of the citrus fruits}

Consumers consider good quality fruits to be those that look good, firm and offer good flavour and nutritional value. If a product is not safe, it does not matter what its quality; it should be eliminated from the product distribution system. Once again, Karl (2000) has earlier noted that the quality of the fruits depends upon the external appearance; fruit size, peel colour, and the degree of peel blemishes and the internal fruit quality-Total Soluble Solids (TSS), acids, plus the degree of bitterness or aromaticity.

The laboratory findings from this work on the effects of the postharvest treatment methods on each quality characteristic of the fruit indicated a significant effect of $p$-value $<001$ for both covered fruits and uncovered fruits as it confirmed by Kader (2002) that the methods of harvesting whether traditional or mechanical can significantly have an impact on the composition and post-harvest quality of fruits.

The findings saw a significant effect of postharvest treatments on the fruit quality characteristics. Concerning covering the fruit treatment, less reduction occurred in fruit weight $(7.70 \%)$, diameter $(9.46 \%)$, and fruit juice weight $(10.60 \%)$. The exposed fruits made a significant reduction in fruit weight $(10.67 \%)$, diameter $(12.53 \%)$, fruit juice weight $(15.60 \%)$ and fruit juice content $(7.70 \%)$. The reduction in fruit weight, diameter, and fruit juice content, and juice weight with ambient storage treatment make the fruits wrinkle and therefore less attractive and acceptable to consumers. The results suggested that holding citrus fruits for up to 28 days could reduce fruit quality and hence it would not be acceptable to some consumers if the storage conditions are not modified. In both treatments, there were inconsistencies in the weekly recordings for vitamin C, TTA, and TSS. Even though there were inconsistencies in the fruits' responses to the treatment, there were significant effects since the $p$-value of the $t$-test was below 0.05 . The general inconsistencies of vitamin C content, TTA, and TSS were expected. According to Cepada et al., (1993), vitamin C (ascorbic acid) contents decreased with time of maturity and prolong storage in citrus fruits. The content of vitamin $\mathrm{C}$ in fruits is influenced by various factors such as genotypic differences, pre-harvest climatic conditions, and cultural practices, maturity and harvesting methods, and postharvest handling procedures (Lee and Kader, 2000). Probably, the inconsistencies could be due to the incomplete synthesis of vitamin $\mathrm{C}$ by precursors which was carried over into storage.

These findings confirmed previous findings that postharvest treatments have a significant effect on fruit quality (Mohammed, 2014; FAO, 2008). However, this study saw no effect on the $\mathrm{pH}$ value for covered fruits while fruits in the sun experienced significant effects. It worth noted that the $\mathrm{pH}$ value obtained from the samples for both covered fruits and uncovered fruits were within the normal range for orange value, 3.6 to 4.3 (Muhammad and Nasir, 2006; Anon, 2004). The study, however, could not determine the possible causes of these inconsistencies. But it could also be attributed to the fact that quality deterioration of harvested fruits happens as a result of a combination of physiological, mechanical, microbiological, and environmental factors and conditions (Rosa and Keerthi, 2008).

\section{CONCLUSION}

Fresh citrus fruits play a significant role in human nutrition, especially as sources of vitamins, minerals, and dietary fibre. Quality, the degree of excellence or superiority, is a combination of attributes, properties, or characteristics that give each commodity value, in terms of its intended use. It is clear from the study that there is an effect of post-harvest treatment on the citrus fruits quality characteristics. From the findings whether the fruits go through the covered treatment process or sun treatment process, they all affect the citrus fruit qualities. However, it was observed that leaving the fruits in the sun has more adverse effects on the fruit quality characters such as fruit juice content, fruit weight, vitamin C, Total Titratable Acidity, and Total Soluble Solid (Brix). It is, therefore, recommended that farmers should be encouraged to cover their fruits after harvest.

\section{REFERENCES}

Anon, (2004)The Orange Book, 2nd ed. Lund, Sweden: Tetra Pak Processing Systems AB.

Aslin S. A. (2014). Role of Citrus Fruits in Health.AslinSanofer.A et al /J. Pharm. Sci. \& Res. Vol. 6(2), 2014, 121- 123

Beatriz A. A.,\& Luis R. L. (2004). Pharmacological properties of citrus and their ancient and medieval uses in the Mediterranean region.Journal of Ethnopharmacology 97, 89-95

Benavente-Garc'ia, O., Castillo, J. (2008). Update on uses and properties of citrus flavonoids: New findings in anticancer, cardiovascular, and anti-inflammatory activity. J Agric Food Chem 56:6185-205.

Cepeda, J.S., Bringas, E., Balz, M., (1993).Ascorbic acid and quality losses of Valencia oranges stored on trees. Horticulture Science, 28:581.

Food and Agriculture Organization (FAO, 2008). Basic Harvest and Post-harvest Handling 
Considerations for Fresh Fruits and Vegetables. Postharvest Training CDRom on Food Processing/FAO manual food handling and preservation/CHAPTER 2

Kader, A.A., ed. (2002). Post-harvest technology of horticultural crops. Oakland: The University of California, Division of Agriculture and Natural Resources Publication $3311,535 \mathrm{pp}$.

Keerthi, B. P., \& Rosa, R. (2008). Good practice for assuring the post-harvest quality of exotic tree fruit crops produced in Jamaica. Food and Agriculture Organization of the United Nations Rome, 20088

Lee, S. K. and Kader, A.A. (2000).Preharvest and postharvest factors influencing vitamin C content of horticultural crops. Journal of Postharvest Biology and Technology20, 207-220

Mohammed, M. (2014). Manual on postharvest management strategies to reduce losses of perishable crops. Piarco, Trinidad, Retrieved from uwi/cta/namdevco conference facility, on 24-2 2016

Muhamad, H. and Nasir, M. (2006). Studying the factors that increase the shelf-life in citrus fruits. URI: http://hdl.handle.net/123456789/27744 Date: 2012-06. Retrieved on 13-8-2015

Orlando, S. P. (2004). Advances in citriculture origin botanical classification and geographical distribution of citrus. Pp1-7.http://www.vedamsbooks.com/. Accessed 2015 July.

Schröeder, H. (2007). Protective mechanism of the Mediterranean diet in obesity and type 2 diabetes. Journal of Nutritional Biochemistry. 18(3):149 - 160

Vanamala, J., Reddivari, L., Yoo K.S., Pike, L.M and Patil, B.S. (2006).Variation in the content of bioactive flavonoids in different brands of orange and grapefruit juices. Journal of Food Composition and Analysis. $19: 157-166$ 